\title{
Brain Granuloma: Rare Complication of a Retained Catheter
}

\section{Andrea laquinandi ${ }^{1}$, Francesco Corrivetti ${ }^{1}$, Pierpaolo Lunardi ${ }^{1}$, Amedeo Ferlosio $^{2}$, Elena Giannini ${ }^{2}$, Federica Novegno ${ }^{1}$}

\author{
Key words \\ - Cerebrospinal fluid \\ - Complication \\ - Cyst \\ - Edema \\ Granuloma \\ - Shunt \\ - Ventricular
}

\section{Abbreviations and Acronyms \\ CSF: Cerebrospinal fluid}

VP: Ventriculoperitoneal

From the Departments of ${ }^{\mathbf{1}}$ Neurosurgery and ${ }^{\mathbf{2}}$ Biomedicine and Prevention, Institute of Anatomic Pathology, University of Rome Tor Vergata, Rome, Italy

To whom correspondence should be addressed:

Federica Novegno, M.D.

[E-mail: federicanovegno@hotmail.it]

Citation: World Neurosurg. (2018) 110:210-216

https://doi.org/10.1016/j.wneu.2017.11.066

Journal homepage: www.WORLDNEUROSURGERY.org

Available online: www.sciencedirect.com

1878-8750/\$ - see front matter @ 2017 Elsevier Inc. All rights reserved.

\section{INTRODUCTION}

Ventriculoperitoneal (VP) shunt is the most frequent treatment for hydrocephalus in children and adults. ${ }^{\mathrm{I}, 2}$ Nonetheless, VP shunting is associated with a large variety of complications, such as obstruction, infection, and disconnection, leading to shunt malfunctioning ${ }^{3,4}$ and the need for surgical revision. Despite significant advances in shunt technology and surgical technique, mechanical dysfunction of the shunt catheter remains a major cause of shunt revision according to the largest series of treated hydrocephalic patients. ${ }^{5-9}$ Sometimes complicated shunt revisions prevent complete removal of the entire shunt system, in particular, the intracranial catheter. The surgeon may decide to leave the catheter in situ if it cannot be easily withdrawn from the ventricle, owing to the risk of cerebral tissue damage and related major bleeding often caused by ventricular plexus adhesions. ${ }^{\text {IO,II }}$ Retained ventricular catheters are not infrequent in daily practice, especially in patients with a long history of VP shunting. ${ }^{\text {I2-I4 }}$ Nevertheless, the decision to retain a ventricular

BACKGROUND: Ventriculoperitoneal (VP) shunt is the most frequent treatment for hydrocephalus. VP shunt malfunction is a very common problem in neurosurgical practice, often requiring shunt revision procedures. In some cases, complete removal of a VP shunt may present difficulties, leading the surgeon to leave the ventricular catheter in situ. This decision is often made to avoid possible adverse events, primarily risk of life-threatening hemorrhage. However, a nonfunctioning catheter left in the ventricular system may lead to further complications.

CASE DESCRIPTION: We report the case of an adult man who presented with a tumor-like cystic lesion, with mural and nodular postcontrast enhancement, caused by a huge granuloma formed around the tip of a retained ventricular catheter.

CONCLUSIONS: This occurrence is extremely rare, and this is the first reported case in the literature. Preoperative differential diagnosis was challenging and included infection, metastasis, dysembryogenetic lesions, and rare reversible porencephalic cysts. According to several physiopathogenetic theories recently reported in the literature, the granuloma may develop as the result of persistent chronic inflammatory reactions between the ventricular catheter left in situ and the brain parenchyma. Application of neuroendoscopic techniques is improving management of VP shunt revisions, allowing safe removal of catheters stuck or lost in the ventricular system. Neuroendoscopy may represent an additional option to avoid possible complications related to retained ventricular catheters.

catheter should weigh the possibility of associated complications (e.g., cerebrospinal fluid $[\mathrm{CSF}]$ infection), onset of new symptoms, and mortality risk. ${ }^{\mathrm{I}-\mathrm{I} 4} \mathrm{We}$ describe a rare case of a pseudotumoral cystic lesion originating as a complication of a retained ventricular catheter in an adult patient who had undergone a VP shunt for posthemorrhagic hydrocephalus.

\section{CASE DESCRIPTION}

A 46-year-old man underwent evacuation of a left parieto-occipital intraparenchymal hemorrhage at another institution in 2009. $\mathrm{He}$ reported severe neurologic sequelae with residual significant cognitive impairment. In the immediate postoperative period, he developed posthemorrhagic hydrocephalus and underwent a right occipito-VP shunt procedure. Owing to onset of acute pancreatitis 2 months after
VP shunt placement, the distal portion of the catheter was disconnected and removed. The ventricular catheter of the shunt and the valve were left in situ, to be promptly reconnected after the resolution of the abdominal disease. Nevertheless, after clinical resolution of pancreatitis, successive control brain imaging scans showed no increase in the ventricular size, and the residual shunt system was not reconnected.

The patient was referred to our department 2 years later because of a right occipital wound dehiscence (Figure 1). He had no signs or symptoms of infection or increased intracranial pressure; thus, he underwent curettage of the wound, valve removal, and permanent closure of the proximal catheter, which was left in situ because it appeared to be stuck to the parenchyma. The postoperative course was uneventful. 

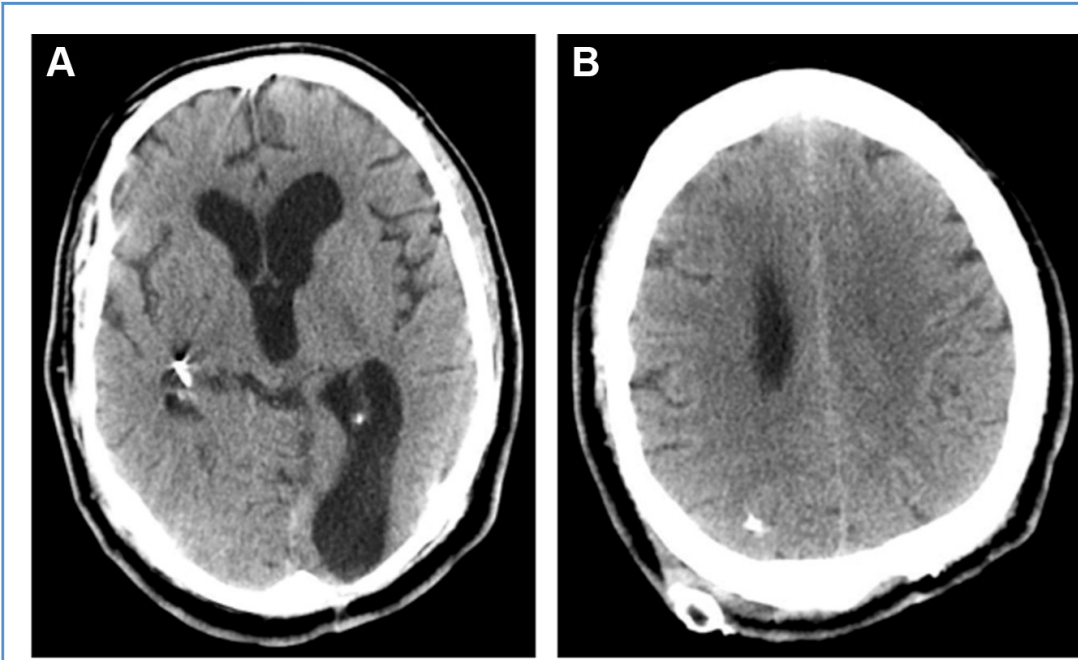

Figure 1. (A and B) Brain computed tomography scan performed in 2011, when the patient presented with wound dehiscence. Images show the residual part of the previous right occipito-ventriculoperitoneal shunt, including the tip of the ventricular catheter $(\mathbf{A})$ and the valve (B). The computed tomography scan documented a dilated ventricular system, unchanged from previous radiologic scans, associated with an area of encephalomalacia in the left hemisphere related to the previous hemorrhage.

Radiologic control imaging performed in the following years showed stability of the ventricular system size (Figure 2); the patient's neurologic conditions likewise did not change. However, after 5 years, he presented with a gradual worsening of clinical status, with drowsiness, gait disturbance, and left hemiparesis.
Computed tomography scans showed the presence of a huge right temporoinsular cystic lesion with a diameter of $5 \mathrm{~cm}$, characterized by perilesional edema. Brain magnetic resonance imaging scans documented a cystic lesion with a posterior solid nodule, characterized by heterogeneous enhancement after contrast injection, resembling a cystic neoplastic lesion (Figure 3).

The patient underwent a right temporal craniotomy and surgical resection of the lesion. Intraoperatively, the cyst was landmarked by means of an ultrasound probe placed $3 \mathrm{~cm}$ deep to the middle temporal gyrus. At this point, a small corticectomy was performed, reaching the cystic component of the lesion, which was opened, revealing limpid CSF. Dissection of the solid portion of the lesion revealed the presence of a tough fibrous nodule surrounding the catheter tip left in situ in the last surgery. Only minimal adherences with the underlying choroidal plexus were found. Both the lesion and the residual ventricular portion were removed (Figure 4).

Histologic examination (Figure 5) revealed a fibrous sclerotic mass comprising diffuse nodular centrally necrotic aggregates of inflammatory cells, partially covered by meninges and choroid plexus. At higher magnification, the inflammatory cells comprised small lymphocytes and reactive xanthomatous macrophages organized in small nodular centrally necrotic aggregates with neutrophils embedded in sclerotic tissue. The diagnosis of granuloma was made. The postoperative course was characterized by significant improvement of the patient's symptoms, with resolution of the

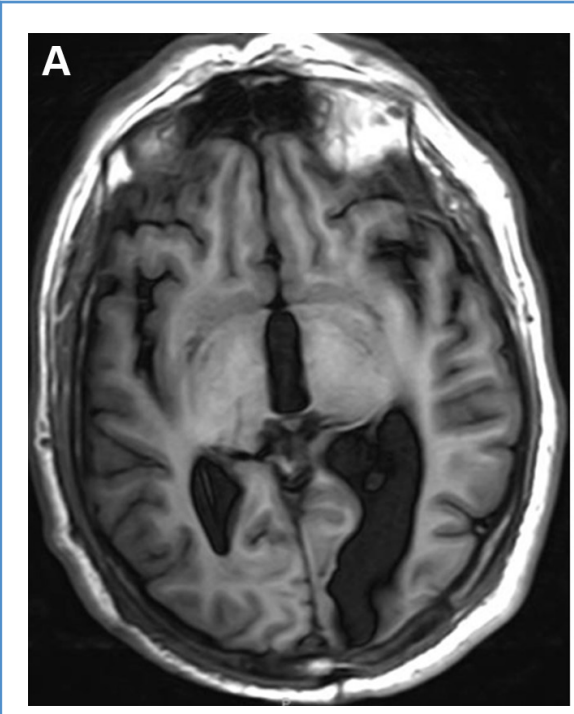

Figure 2. (A-C) Postoperative axial T1-weighted magnetic resonance imaging showing a slight enlargement of the ventricular system associated
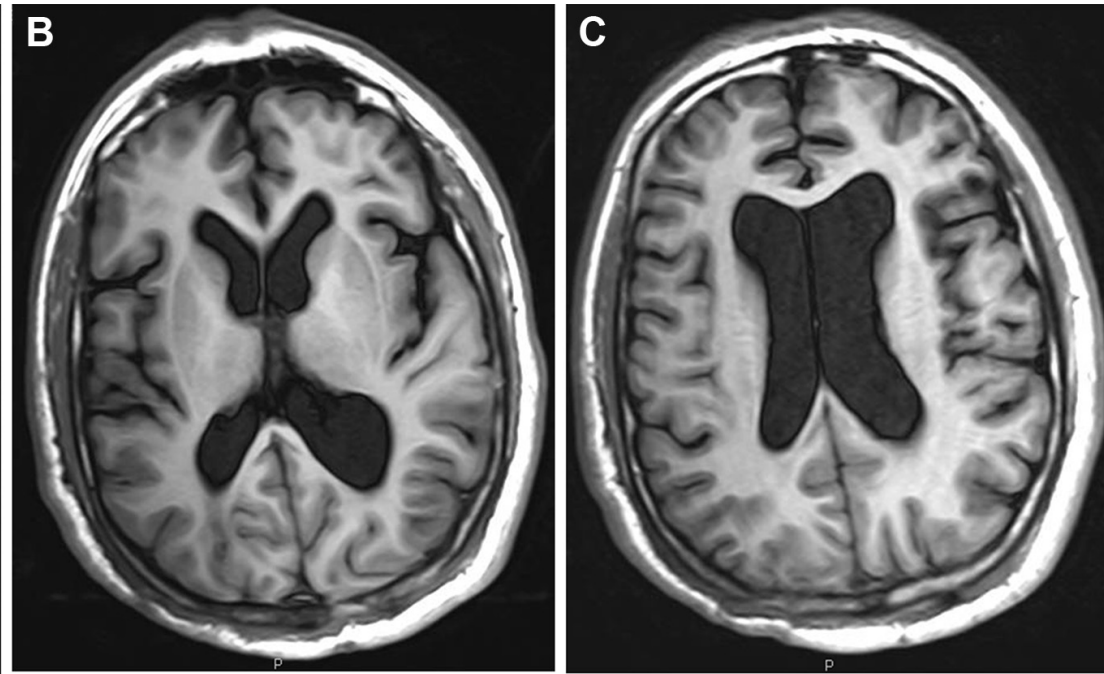

with the known area of encephalomalacia in the left hemisphere. The size of the ventricles remained unchanged during follow-up. 


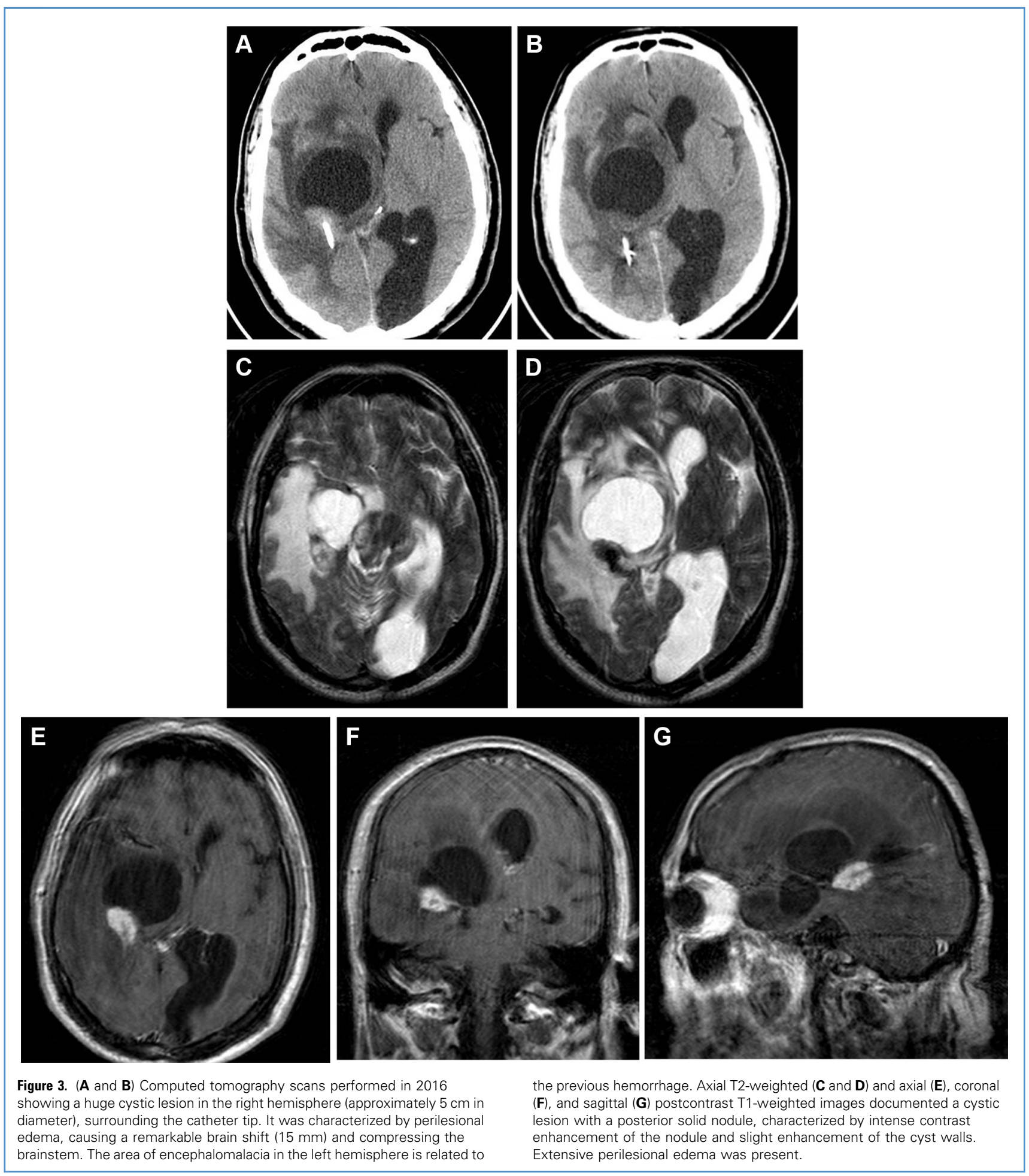

drowsiness and progressive recovery of the motor deficit. Postoperative magnetic resonance imaging demonstrated total excision of the lesion, optimal brain decompression, and persisting ex vacuo ventricular enlargement (Figure 6). At last follow-up I year later, the patient's clinical condition and radiologic examinations were stable. 


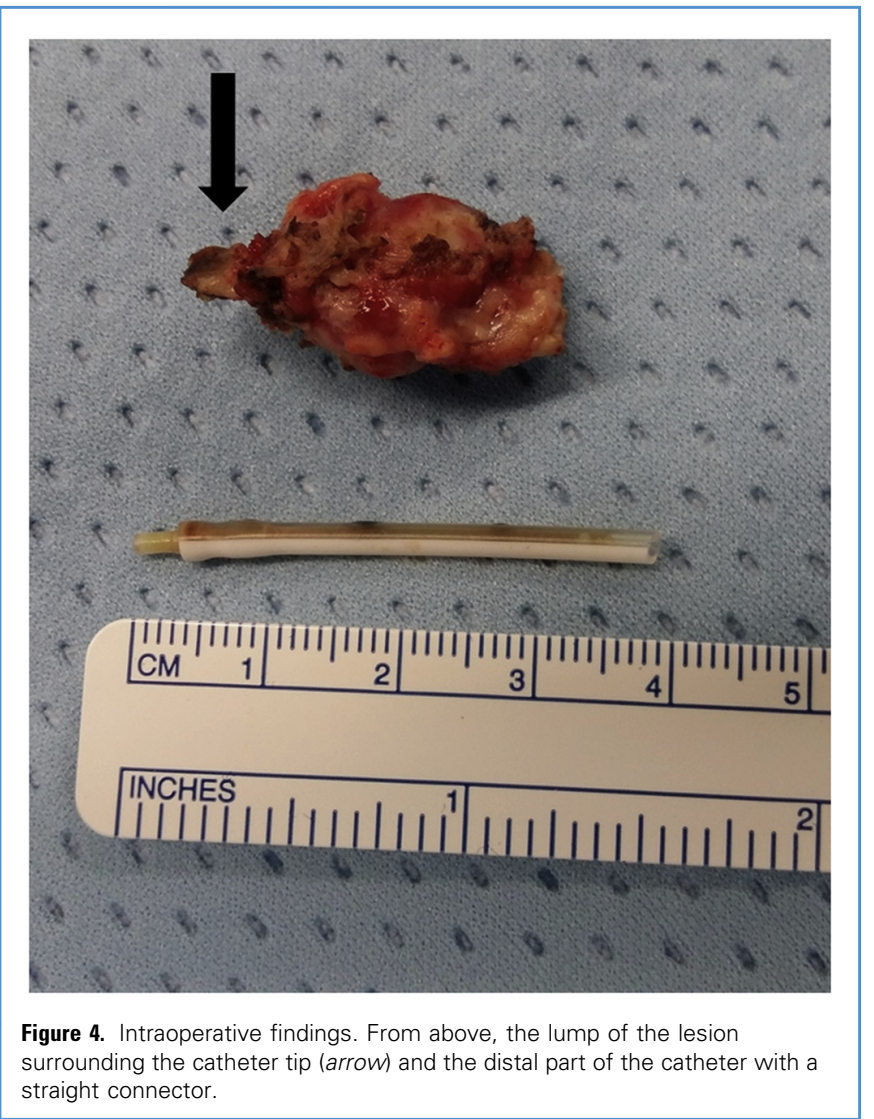

\section{DISCUSSION}

We report a unique case concerning an extremely rare complication of a retained ventricular catheter. Our patient developed a tumor-like cystic lesion with mural and nodular enhancement, which turned out to be a granuloma. Our literature review did not reveal any similar case reported so far. The known shunt-associated cyst, also called by some authors reversible porencephalic cyst, ${ }^{\mathrm{I}, \mathrm{I5}-20}$ represents a rare complication of shunt obstruction. However, these cysts are not comparable to our case in terms of both the physiopathogenetic mechanism and the radiologic appearance. Indeed, shuntassociated cysts are thought to develop as a consequence of migration of the CSF into the white matter surrounding the ventricular catheter, induced by the elevated intracranial pressure of obstructed shunts. In most of these cases, revision or removal of the VP shunt led to cyst regression and resolution of neurologic impairments.

\section{Differential Diagnosis}

An early radiologic diagnosis was challenging. The differential diagnosis included infection, metastasis, and dysembryogenetic lesions, owing to the cystic tumor-like appearance enhancing after contrast injection associated with perilesional edema. ${ }^{2 I}$ A cystic lesion with a mural enhancing nodule could evoke an hemangioblastoma or a pilocytic astrocytoma in an atypical localization. ${ }^{22}$ Also, a pleomorphic xanthoastrocytoma ${ }^{23}$ and, more rarely, a cystic meningioma ${ }^{24}$ may be present. Extremely rare tumoral entities, such as cystic metastasis, tanycytic ependymoma, intracerebral schwannoma, and rosette-forming glioneuronal tumor of the fourth ventricle, have been seldom described in the literature. ${ }^{2 \mathrm{I}}$ However, besides the intraoperative cystic appearance and intracystic fluid composition, each of these tumors has typical characteristics of localization, age of onset, and neuroimaging features that may allow a preoperative differential diagnosis. ${ }^{2 \mathrm{I}} \quad$ Nonetheless, only the histopathologic examination allowed us to confirm the definitive diagnosis.

Granuloma of the Retained Catheter: The Physiopathogenetic Issue

The final diagnosis was a granuloma originating around the ventricular catheter. Several theories have described different types of biologic reaction between a ventricular catheter and brain parenchyma and their timing of onset. ${ }^{25-28}$ These can be explained according to the following 3 -step physiopathogenetic theory suggested by Sarkiss et al. ${ }^{9}$ :

I. The mechanical trauma during positioning of the intraventricular catheter initiates an inflammatory process similar to wound healing with an inflammatory response leading to recruitment of microglial cells and scar formation. These processes can determine an early onset of catheter obstruction ( $<6$ months $).{ }^{29,30}$

2. The protracted phase of foreign body reaction or a delayed immune reaction results in chronic inflammation and formation of astroglial scarring. The glial scar itself initiates a foreign body reaction and may lead to alterations in the biologic properties of the silicone shunt tubing, contributing to late shunt obstructions (6 months to 3 years). Activated macrophages are unable to digest the foreign body, creating multinucleate giant cells with release of proinflammatory mediators.

3. Late effects of foreign body response are represented by mineralization of the shunt tube and vulnerability to breaks or to degradation ${ }^{3-33}$ determining late malfunctioning of the VP shunt catheter $(>3$ years)

In cases of late obstruction, a particular concern is related to the shunt material. Over time, barium-impregnated and silicone rubber catheters have been replaced by plain silicone-coated catheters to avoid the occurrence of late calcification. Nevertheless, a delayed hypersensitivity reaction to the silicone has been reported in some cases, leading to the introduction of polyurethane-based systems. ${ }^{9}$ The effectiveness of the latter 

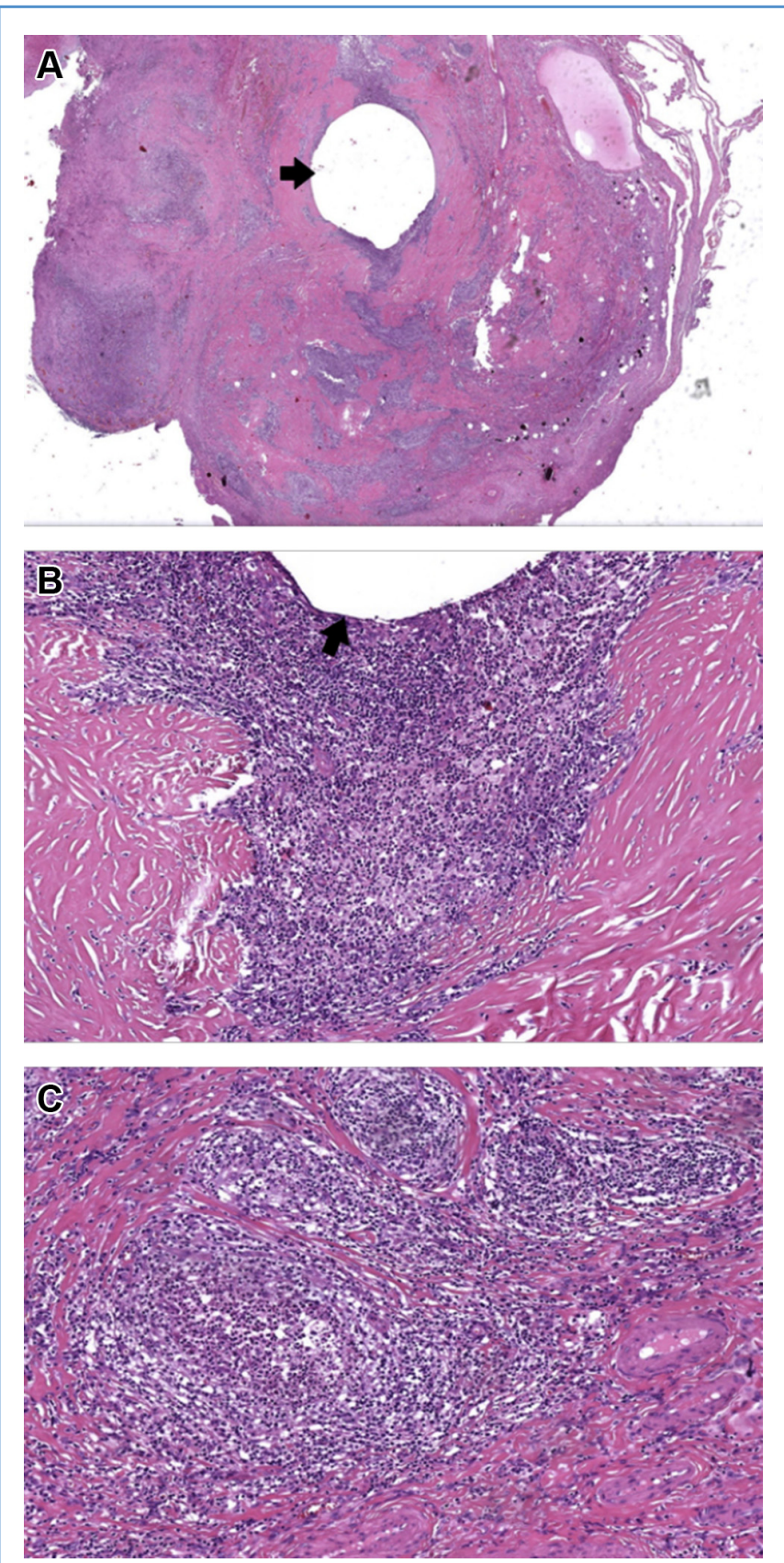

Figure 5. (A) Representative histologic stain of surgically removed mass showing the right choroid plexus, underlying reactive meninges with many psammoma bodies, and fibrous sclerotic tissue with diffuse chronic

inflammatory infiltration and hemorrhages (original magnification, 10x).

(B and C) At higher magnification, the inflammatory cells comprised small lymphocytes and reactive macrophages with xanthomatous aspect organized in small nodular centrally necrotic aggregates with neutrophils embedded in sclerotic tissue (original magnification, $100 \times$ ). Arrow in $(\mathbf{A}$ and $\mathbf{B}$ ) indicates the hole where the catheter laid.

materials, with regard to their ability to activate a late foreign body reaction, still needs to be proved. Other materials, such as cotton fibers (from cottonoids used during surgery), human hair, or talc granules, may induce a foreign body reaction as well. ${ }^{34}$ In addition to these physiopathogenetic mechanisms, there is further evidence that tissue with proliferative capability is prone to cause catheter obstruction. Indeed, blocked shunt revision is most frequently due to choroid plexus tissue $(80 \%)$, particularly in cases of catheter tips placed behind the foramen of Monro. Brain tissue (astrocytes), leptomeninges, hemosiderin, and blood clots trapped inside the catheter during its insertion can be involved in the inflammatory reaction. ${ }^{34}$

In our case, the lesion we found was a granuloma of the tip of the catheter left in situ. This appeared to have migrated forward after the previous operation. Tiny fibrous adherences were found between the granuloma and the choroid plexus. The magnetic resonance imaging sequences had depicted a slight enhancement of the cyst walls, mimicking a cystic tumor with enhancing nodule. However, intraoperatively, the cystic component of the lesion was opened, revealing only CSF content. There was no evidence of cyst linings, which turned out to be the ependyma of the temporal horn. We may hypothesize that the forward migration of the retained catheter reaching the choroid plexus along with the formation of the granuloma led to the temporal horn occlusion and development of the cystic component. The slight enhancement of its linings may be explained as the occurrence of local ependymal inflammation.

\section{Surgical Considerations}

Complete removal of the shunt device should be the treatment of choice in shunt revision surgery. However, in case of adherences between the catheter tip and brain parenchyma or choroid plexus, the risk of hemorrhagic complications is considerable and may lead the surgeon to leave the ventricular catheter in place. ${ }^{\text {IO-I4 }}$ Nonetheless, a retained ventricular catheter represents a prosthetic device that has become unnecessary and is associated with further severe complications. ${ }^{\text {I2-I }}$ Therefore, several maneuvers are commonly used to aid removal, including gentle traction on the catheter, rotation of the catheter, placement of a hemostatic clip on the protruding catheter and allowing the weight of the clip to provide traction, and intraluminal choroid plexus 

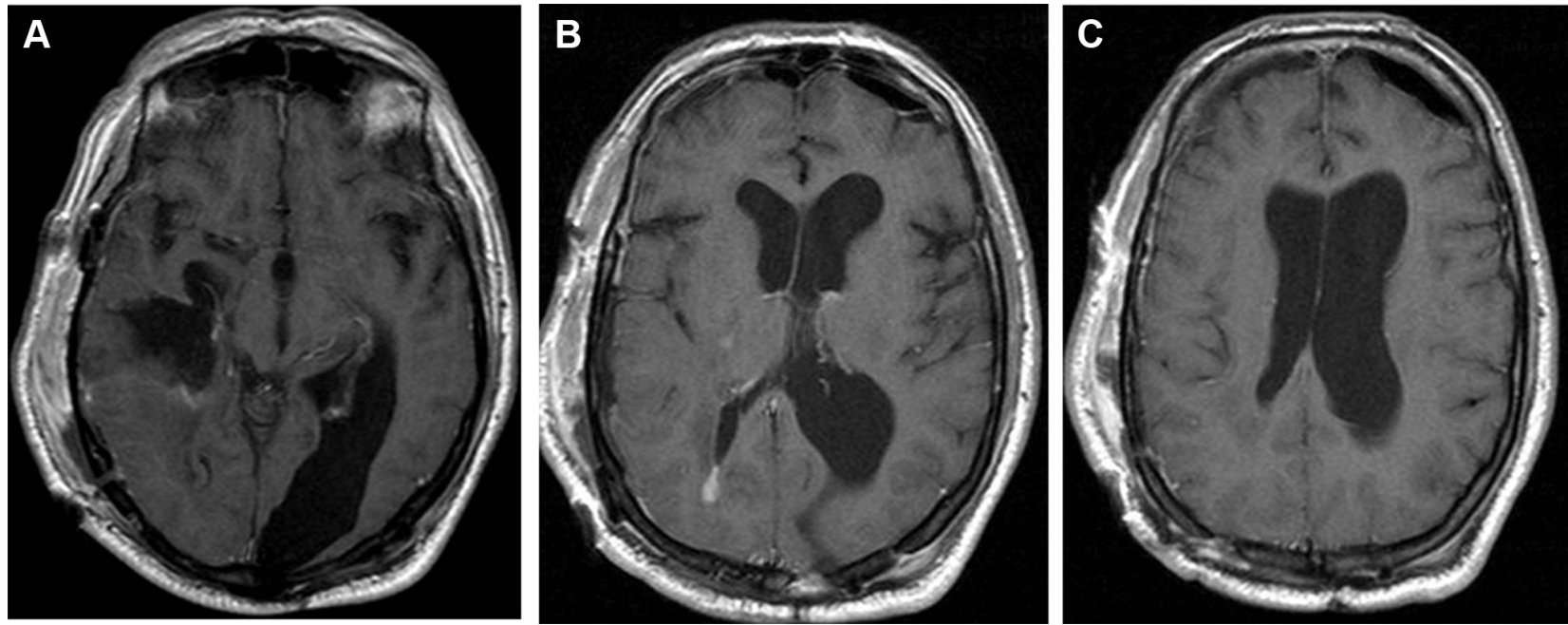

Figure 6. (A-C) Postoperative axial postcontrast control T1-weighted magnetic resonance imaging showing complete resection of the cystic

lesion. The ex vacuo ventricular enlargement did not change significantly. coagulation. ${ }^{\text {II }} \quad$ Sometimes these maneuvers fail and result in a retained ventricular catheter. ${ }^{\text {II }}$

Advancements in neuroendoscopic techniques are creating additional options in dealing with complicated and difficult cases of nonfunctioning retained catheters. ${ }^{\mathrm{I}}{ }^{3}$ Neuroendoscopy offers direct vision during traction maneuvers, individuating the presence of adherences, which may be coagulated to prevent major intraventricular bleeding. Neuroendoscopy can also be easily applied for removal of ventricular catheters that have been left or lost in the ventricular system, allowing their recognition and retrieval in a rapid and safe way. ${ }^{\mathrm{I}}$

\section{CONCLUSIONS}

VP shunt is the most frequent treatment for hydrocephalus, but it is associated with a large variety of complications that may lead to several shunt revisions during a patient's lifetime. Complete removal of the shunt device should be the treatment of choice in shunt revision surgery. However, removal may be difficult, and the surgeon may decide to leave the ventricular catheter in situ to avoid possible complications. To our knowledge, this is the first case described in the modern literature of a tumor-like cystic lesion manifesting as a complication of a retained ventricular catheter in an adult patient. The benefits of leaving in situ a ventricular catheter and the risks of producing more severe sequelae need to be counterbalanced. Application of neuroendoscopic techniques is improving the management of VP shunt revision procedures. In our opinion, neuroendoscopy is a valuable tool for removal of ventricular catheters stuck or lost in the ventricular system, allowing control of the possible hemorrhagic complications.

\section{REFERENCES}

I. Bianchi F, Frassanito P, Tamburrini G, Caldarelli M, Massimi L. Shunt malfunction mimicking a cystic tumour. Br J Neurosurg. 20I6;6: $\mathrm{I}-3$

2. Pan IW, Harris DA, Luerssen TG, Lam SK. Comparative effectiveness of surgical treatments for pediatric hydrocephalus [e-pub ahead of print]. Neurosurgery. 2017. https://doi.org/Io.1093/ neuros/nyx440.

3. Borgbjerg BM, Gjerris F, Albeck MJ, Hauerberg J, Børgesen SE. Frequency and causes of shunt revisions in different cerebrospinal fluid shunt types. Acta Neurochir (Wien). I995;I36:I89-I94.

4. Puca A, Anile C, Maira G, Rossi G. Cerebrospinal fluid shunting for hydrocephalus in the adult: factors related to shunt revision. Neurosurgery. I99I;29:822-826.

5. Olsen L, Frykberg T. Complications in the treatment of hydrocephalus in children. A comparison of ventriculoatrial and ventriculoperitoneal shunts in a 20-year material. Acta Paediatr Scand. 1983;72: 385-390.
6. Sainte-Rose C, Piatt JH, Renier D, Pierre-Kahn A, Hirsch JF, Hoffman HJ, et al. Mechanical complications in shunts. Pediatr Neurosurg. I991;17:2-9.

7. Sayers MP. Shunt complications. Clin Neurosurg. 1976;23:393-400.

8. Bierbrauer KS, Storrs BB, McLone DG, Tomita T, Dauser R. A prospective, randomized study of shunt function and infections as a function of shunt placement. Pediatr Neurosurg. I990;16: 287-29I.

9. Sarkiss CA, Sarkar R, Yong W, Lazareff JA. Time dependent pattern of cellular characteristics causing ventriculoperitoneal shunt failure in children. Clin Neurol Neurosurg. 2014;127:30-32.

Io. Becker DP, Nulsen FE. Control of hydrocephalus by valve-regulated venous shunt: avoidance of complications in prolonged shunt maintenance. J Neurosurg. I968;28:215-226.

II. Whitfield PC, Guazzo EP, Pickard JD. Safe removal of retained ventricular catheters using intraluminal choroid plexus coagulation. Technical note. J Neurosurg. I995;83:IIOI-IIO2.

I2. Gupta R, Mohindra S, Dhingra AK. Are nonfunctioning intraventricular shunt catheters really dormant? Br J Neurosurg. 2007;2I:297-298.

13. Khan SA, Gretchel A, Govender H, Hartzenberg B. Brain abscess and granuloma formation as late complications of retained ventricular catheter. Neurol India. 2009;57:489-492.

I4. Pettorini BL, Frassanito P, Tamburrini G, Massimi L, Caldarelli M, Di Rocco C. Retrieval of ventricular catheter with the aid of endoscopy: technical note. J Neurosurg Pediatr. 2008;2:71-74.

15. Sugimoto K, Enomoto T, Nose T. Reversible porencephaly. Alteration of the cerebrospinal fluid 
flow after shunt malfunction. Childs Nerv Syst. IggI; 7:394-398

I6. Vajramani GV, Fugleholm K. Reversible CSF cys related to a functioning ventriculo-peritonea shunt. Acta Neurochir (Wien). 2005;I47:II99-I202.

I7. Sakamoto H, Fujitani K, Kitano S, Murata K, Hakuba A. Cerebrospinal fluid edema associated with shunt obstruction. J Neurosurg. I994;8I: I79-183.

I8. Owen R, Pittman T. Shunt malfunction presenting with cerebral edema. Pediatr Neurosurg. 2003;38: IIO-II2.

I9. Ozeki M, Funato M, Teramoto T, Ohe N, Asano T, Kaneko $\mathrm{H}$, et al. Reversible cerebrospinal fluid edema and porencephalic cyst, a rare complication of ventricular catheter. J Clin Neurosci. 2010;17 658-66r.

20. Sinha AK, Lall $R$, Benson $R$, O'Brien DF, Buxton N. Intraparenchymal pericatheter cyst following ventriculoperitoneal shunt insertion: does it always merit shunt revision? Zentralbl Neurochir. 2008;69:I52-I54.

2I. Raz E, Zagzag D, Saba L, Mannelli L, Di Paolo PL, D'Ambrosio F, et al. Cyst with a mural nodule tumor of the brain. Cancer Imaging. 20I2;I2: $237-244$.

22. Shih RY, Smirniotopoulos JG. Posterior fossa tumors in adult patients. Neuroimaging Clin N Am. 2016;26:493-510.
23. Koeller KK, Henry JM. From the archives of the AFIP: superficial gliomas: radiologic-pathologic correlation. Armed Forces Institute of Pathology, Radiographics. 200I;21:1533-1556.

24. Hu SL, Li F, Hu R, Cui G, Meng H, Feng H. Atypical histopathologic type of cystic meningioma. Acta Neurochir (Wien). 2010;152:I05-109.

25. Collins P, Hockley AD, Woollam DH. Surface ultrastructure of tissues occluding ventricular catheters. J Neurosurg. 1978;48:609-6r3.

26. Del Bigio MR, Fedoroff S. Short-term response of brain tissue to cerebrospinal fluid shunts in vivo and in vitro. J Biomed Mater Res. I992;26:979-987.

27. Guevara JA, La Torre J, Denoya C, Zúccaro G. Microscopic studies in shunts for hydrocephalus. Childs Brain. I98I;8:284-293.

28. Kossovsky N, Snow RB. Clinical-pathological analysis of failed central nervous system fluid shunts. J Biomed Mater Res. I989;23(AI suppl): $73-86$.

29. Polikov VS, Tresco PA, Reichert WM. Response of brain tissue to chronically implanted neural electrodes. J Neurosci Methods. 2005; I48:I-I8.

30. Schmidt S, Horch K, Normann R. Biocompatibility of silicon-based electrode arrays implanted in feline cortical tissue. J Biomed Mater Res. I993;27: I393-I399.
3I. Boch AL, Hermelin E, Sainte-Rose C, Sgouros S. Mechanical dysfunction of ventriculoperitonea shunts caused by calcification of the silicone rubber catheter. J Neurosurg. 1998;88:975-982.

32. Echizenya K, Satoh M, Murai $\mathrm{H}$, Ueno $\mathrm{H}$, Abe $\mathrm{H}$, Komai T. Mineralization and biodegradation of CSF shunting systems. J Neurosurg. I987;67: 584-591.

33. Jimenez DF, Keating R, Goodrich JT. Silicone allergy in ventriculoperitoneal shunts. Childs Nerv Syst. I994;10:59-63.

34. Sekhar LN, Moossy J, Guthkelch AN. Malfunctioning ventriculoperitoneal shunts. Clinical and pathological features. J Neurosurg. I982;56: 4II-4I6.

Conflict of interest statement: The authors declare that the article content was composed in the absence of any

commercial or financial relationships that could be construed as a potential conflict of interest.

Received 17 October 2017; accepted 11 November 2017

Citation: World Neurosurg. (2018) 110:210-216.

https://doi.org/10.1016/j.wneu.2017.11.066

Journal homepage: www.WORLDNEUROSURGERY.org

Available online: www.sciencedirect.com

1878-8750/\$ - see front matter ( 2017 Elsevier Inc. All rights reserved. 